\title{
Bringing Bauhaus Back: Digital Architecture + Contemporary Craft
}

\author{
SHELBY ELIZABETH DOYLE \\ lowa State University
}

"The Bauhaus believes the machine to be our modern medium of design and seeks to come to terms with it." -Walter Gropius, The Theory and Organization of the Bauhaus

German architect Walter Gropius founded the Bauhaus in 1919 and after fourteen prolific years, it closed. Despite its short tenure, the ramifications of the Bauhaus are still present in architectural education and practice. Its core objective was a radical, and still unrealized, concept: the unity of art and technology. The introduction of contemporary digital tools, techniques, and materials make this unity possible in new and profound ways thereby extending the Bauhaus project into the present day as a meaningful model for architectural education and digital craft.

\section{INTRODUCTION}

The most significant achievement of the Bauhaus may be its nurturing of a sustained cross-media conversation about the nature of art in the modern age. Gropius explained his vision for a union of art and design in the Proclamation of the Bauhaus, which described a utopian craft guild combining architecture, sculpture, and painting into a single creative expression. The reemergence and refinement of this vision can be seen in interdisciplinary (anti-disciplinary) design research groups such as the MIT Media Lab which exist at the convergence of technology, multimedia, science, art, and design. This paper explores architectural models for reviving specific aspects of Bauhaus pedagogies that adapt and further the project of architectural education. Rather than a resuscitation of Modernism this research considers ways in which architects, operating in a digital culture, can be designers of constructive systems and provide the foundation of a new tectonic culture.

Examples of this new turn include architectural pedagogies, research labs, and degree programs that rely upon the arrival of digital fabrication shops in architectural departments and the emergence of new and exploratory design/build programs. These educational approaches invert the gap between teaching and professional practice by introducing direct production control, digital craft, speculative projects, and methods for re-centering the architect's role around the act of construction rather than coordination.

The questions raised by the conditions of contemporary practice and its continuous introduction of new technologies demand an architectural education model that explores shifting boundaries between the physical and electronic worlds. This paper concludes with an examination of how the Bauhaus provides a framework for this transition. In an age of digital social networks, the future of built and public spaces will largely depend on an architectural education that navigates interaction between the physical and the virtual. This digital realm is an extension of the imaginary space of design, rather than the replacement for architecture or physical space.

Digital walls do not keep out physical rain or as Malcom McCullough states there is "the seeming paradox of intangible craft." Rather, digitally controlled manufacturing and fabrication extend digital architecture into physical space and lead to a realization of the architect-craftsman that John Ruskin sought to revive, but through methods Ruskin could not have anticipated. The future of architectural education should include reflections on the Bauhaus architect-craftsman: "The ultimate goal of all visual artistic activity is construction!... Let us establish a new guild of craftsmen without the presumption of class distinctions building a wall of arrogance between craftsmen and artists." Or more simply put: "Build, don't talk." (Ludwig Mies Van Der Rohe)

\section{ARCHITECTURE AS PROFESSION + DISCIPLINE}

"Architecture today has forfeited its status as a unifying art"

-Walter Gropius

Emigration from Germany during the 1930s brought the methods of the Bauhaus to North America at a time while the discipline and profession were still searching for a uniquely American identity. In North America the institutionalized practice and study of architecture began in the late nineteenth century concurrent with the broader emergence of professionalism and the research university. The Bauhaus model was disruptive to these developments. It emphasized innovation and was seen as an alternative to the Beaux Arts system's emulation of the works of the past. Its curriculum was built around 


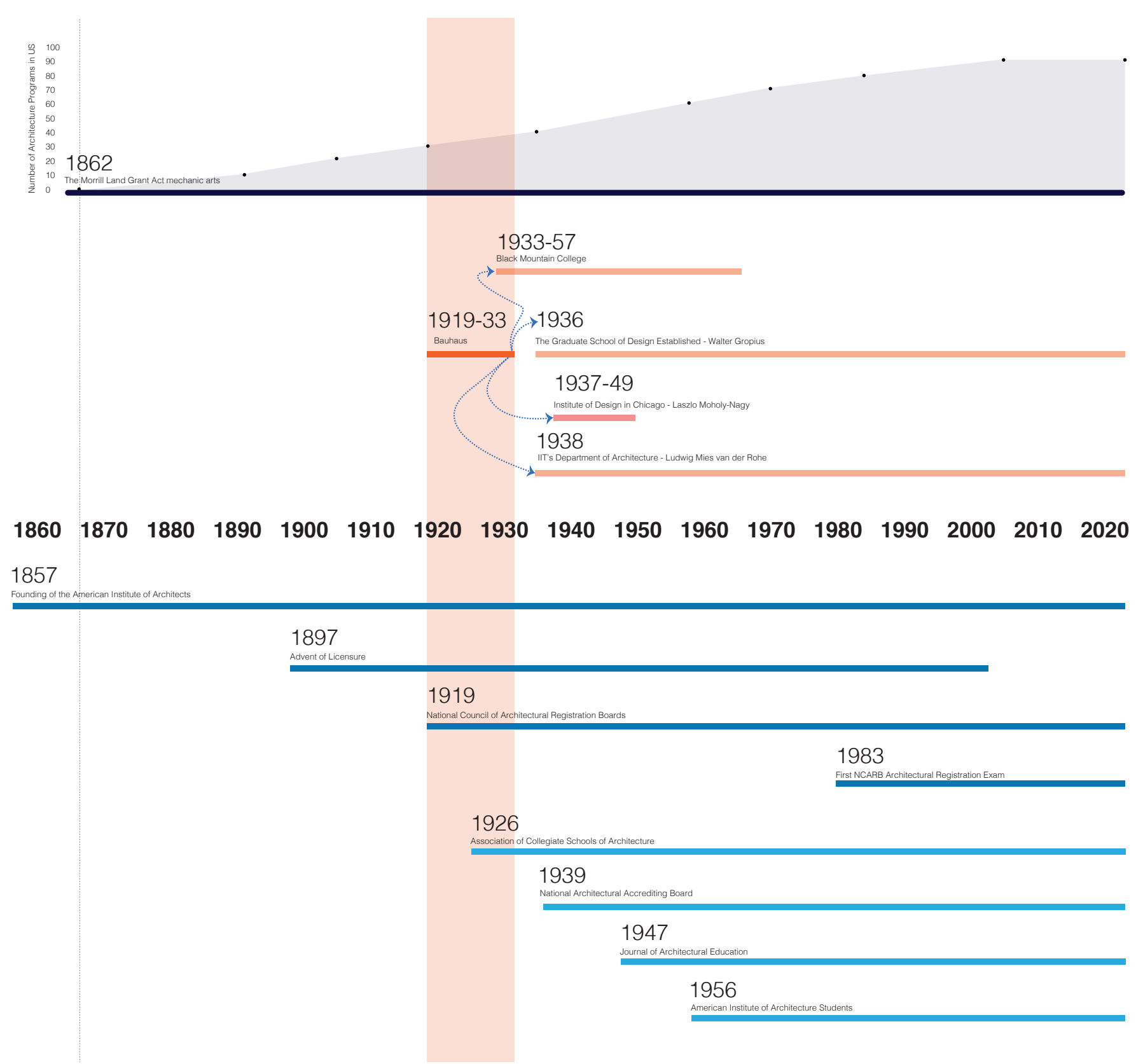

Figure 1. Concurrent threads in the development of the architectural discipline and profession.

workshops and laboratories where students carried out collaborative hands-on building projects. Ranging from experiential education work sites, collective effort, and community service, the Bauhaus workshops resonated with the educational theories of the American Pragmatist philosopher John Dewey, who placed experience at the center of learning. Dewey saw the teacher not as a lecturer to an audience but an active partner in the learning process and conceived of schools as social instruments that should harness young peoples 'impulses and tendencies to make, to do, to create (and) to produce, whether in the form of utility or of art." A cohesive summary of the development of American architectural education can be found in Joan Ockman's Architecture School: Three Centuries of Educating Architects in North America.
As architectural education became increasingly institutionalized it found itself inextricably bound up with professional norms through the protocols of accreditation and licensure. The profession intended to serve the public interest and thereby earn the public's trust through institutional structures. This left the academic discipline in an ongoing search for an identity that was separate from that of the profession.

Figure 1 brings together a series of concurrent strains influencing the development of the discipline and profession of architecture. Graph 1 identifies the first formal architecture curriculum in 1865 and the subsequent increase of programs until the present day. Graph 2 places the Bauhaus in the context of the development of the North American architectural system and identifies its transition to North 
America: Black Mountain College, The Graduate School of Design, Institute of Design, and IIT's Department of Architecture. Graph 3 addresses the institutionalization of professional practice through the establishment of the American Institute of Architects, the development of licensing requirements and the National Council of Architectural Registration Board. Graph 4 addresses the institutionalization of the academic discipline of architecture: the establishment of the National Architectural Accreditation Board, the Association of Collegiate Schools of Architecture, the publication of the Journal of Architectural Education, and the introduction of the American Institute of Architecture Students.

A series of characteristics drawn from the Bauhaus may provide a counterpoint to the professionalization of the architectural academy: embracing an anti-academic spirit against disciplinary stricture, focusing on everyday life, addressing anxieties about the soullessness of manufacturing and its products, challenging fears about architecture's loss of purpose in society, stressing intellectual and theoretical pursuits, and linking these to an emphasis on practical skills, crafts and techniques, and finally leveling the old hierarchy of design disciplinary silos and hierarchies. Today the architectural discipline's boundaries are extraordinarily fluid, which affords architecture the capacity to modify its claims to knowledge, modes of production, and range of projects. Schools of architecture are faced with an unusual opportunity and responsibility to explore and scrutinize these rapidly evolving interests and endeavors by drawing on their own complex history of research and speculation. Of particular potency is the reintroduction of craft and the craftsman to architectural education.

\section{DEFINING CRAFT}

"Let us create a new guild of craftsmen, without the class distinctions which raise an arrogant barrier between craftsman and artist." Walter Gropius

Gropius lauded craft and the craftsmen. A closer look at what it means to craft reveals the political and social potential of craft as a pedagogic framework. The term craft is derived from the Middle English craeft, meaning strength and skill. Craft can also be associated with the professional affiliation of a guild or trade association. It first came into widespread use in conjunction with the advent of guilds - self-protective medieval associations or private clubs of artisans with formally cultivated talents rooted in innate and rare abilities. Craft creates intimate relations between problem solving and problem finding, technique and expression, play and work. (Sennett, 2008) It brings to mind material, matter, repetition, talent, time, pride and dedication. Craft comes burdened with accusations of nostalgia, Luddite tendencies and perhaps even a regressive attachment to the past and the pre-industrial. In the mid 17th century Denis Diderot spent the better part of twenty years identifying and documenting crafts. The result: The Encyclopedia, or Dictionary of Arts and Crafts, exhaustively recorded how practical things are accomplished and proposed ways to improve them. In The Encyclopedia Diderot, places manual pursuits on equal footing with mental labors, asserting that the craftsman's labors were icons of the
Enlightenment. He also scorned hereditary members of the elite who did no work and so in Diderot's opinion contributed nothing to society. His definition of craft is as follows:

"CRAFT. This name is given to any profession that requires the use of the hands, and is limited to a certain number of mechanical operations to produce the same piece of work, made over and over again. I do not know why people have a low opinion of what this word implies; for we depend on the crafts for all the necessary things of life."

-Denis Diderot, The Encyclopedia 1747-1765.

As can be seen in Diderot's explanation, the idea of craft and its embodiment of the thinking maker produced discomfort as it upset a social order where thinking and making were separated and making subordinate to thinking. This separation is not new; it extends to the very foundations of philosophy. As Jacques Ranciere demonstrates in his book The Philosopher and His Poor: "So there is only one principle of exclusion (from political life). Plato's Republic does not decree that one cannot be a shoemaker and a citizen at the same time. It simply establishes that one cannot be a shoemaker and a weaver at the same time..." (Ranciere, 2004) In doing so Plato sets forth that the shoemaker has only been given enough time to do one thing and therefore cannot encroach on the monopoly of thought and leisure that the philosopher enjoys. The thinking-maker disrupts the neat hierarchical social order which preferences the philosopher, as thinker, over the artisan, as laborer. The introduction of digital tools and technologies further undermines traditional hierarchies and social orders.

\section{DEFINING DIGITAL CRAFT}

"The best way to appreciate the merits and consequences of being digital is to reflect on the differences between bits and atoms." -Nicholas Negroponte, Being Digital (Negroponte, 1995)

What happens then if architecture cedes craft to the digital realm? Or rather, gives up the very thing, which gave it agency in the first place? Is the digital realm an extension of the imaginary space or a replacement for physical space? And does this cyberspace extend architectural agency or limit it? Issues of dimension, heft, tactility, and materiality remain essential to architecture as built environment, no matter how tantalizing the pixilated world may be. Digital fabrication and its associated tools provide a tactile counterpoint to the image-based environment otherwise prevalent in digital work. For the purpose of this paper, the digital turn in architecture occurred in the early 1990s and is defined as the computerization of design, construction, and fabrication processes. This is marked by a transition from designs based upon a Cartesian grid to those constructed from a digital field condition abstracted within computational space. Specifically, the introduction of continuous computational splines that are variable within defined limits and can be notated as parametric functions or mathematical relationship between parts. (Carpo, 9)

Digital craft emerges from computational thinking, digital fabrication and robotic construction; processes that allow the full participation 


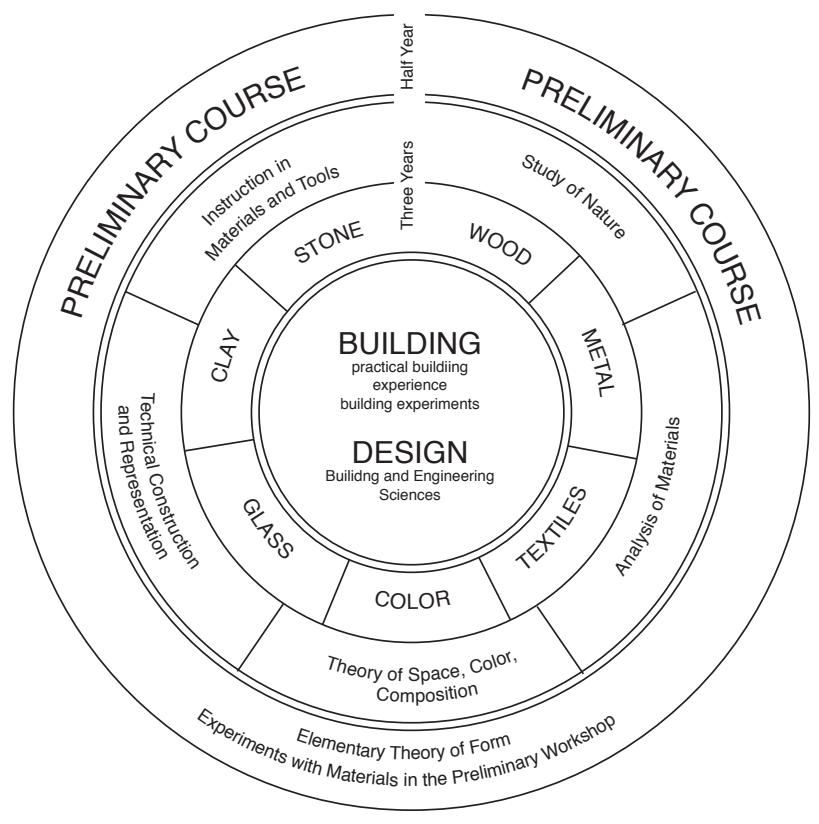

Figure 2. To left is the Bauhaus curriculum and to the right is a proposed expansion and retooling of this curriculum in response to the advent of computational and digital technologies.

of architects in the production of buildings and thereby extend architecture's agency to engage in a larger social and political project. A close reading of the Human Condition demonstrates that the spheres presented by Hannah Arendt: labor, work, and action are interconnected and in the present day are merged through architectural technology to extend the participation of architects in the construction process beyond the cultural and physical confines of bodily practice.

Craft has long been seen as the antithesis of the evils of modernity and industrialization. Against the rigorous perfection of the machine, the craftsmen became an emblem of human individuality, symbolized by the positive value placed on variations, flaws and irregularities in handiwork. The capacity to craft, to think through making, instills architecture with an explicit agency to engage outside of the academy and the discipline. The introduction of digital craft into contemporary practice extends, rather than limits, this agency in the social (or political) project of architecture. The process of thinking through making and the accompanying non-linear methods position architects to identify pathways of thought into contemporary issues, and then make visible that which remains unseen to other disciplines. Craft encourages imagination and through imagination the architect enters into the spheres of life, which are not immediate to personal experience: the social (or political) project of architecture. This imagination is a powerful agent as well. The ability to imagine a better world equipped with the capacity to act, is to craft an object with intentionality and purpose. As the discipline continues to struggle with self-identity and the direction of its fragmented authority,

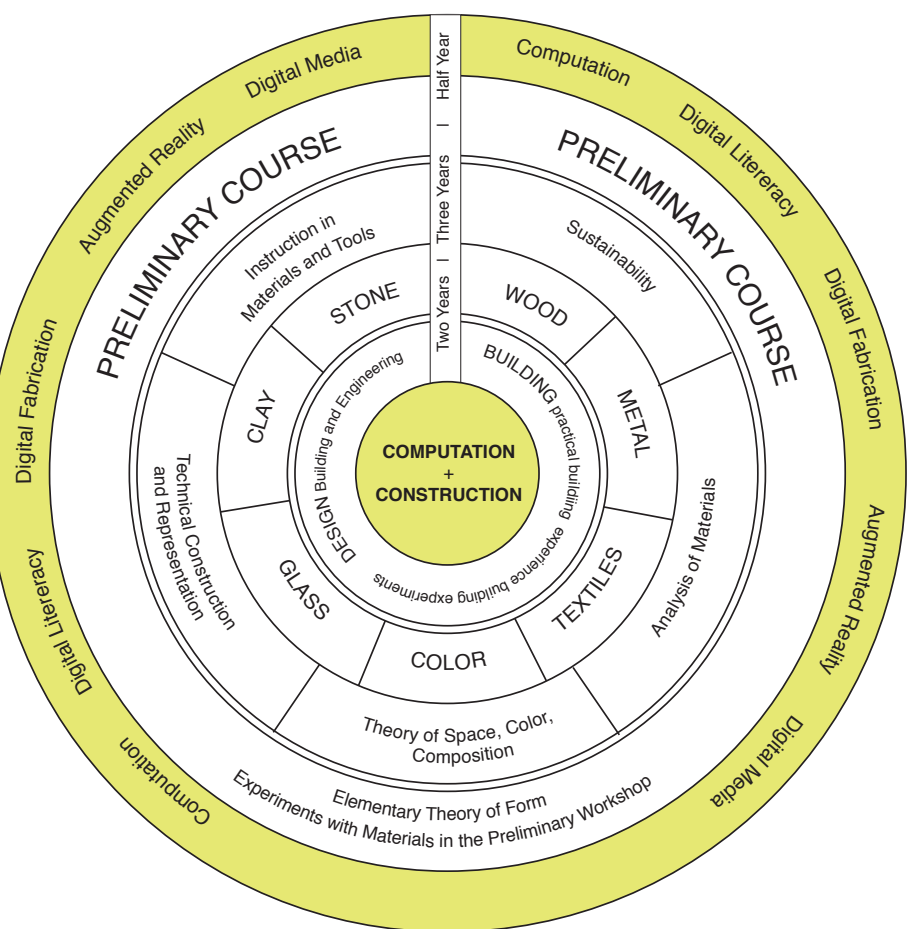

craft remains the most valuable tool at the architect's disposal, as Gropius espoused.

\section{UNITY OF ART + TECHNOLOGY}

"We are gathering experiments." - Josef Albers

Digital technologies have indelibly transformed the visual language of design education, supplanting traditional hand-made drawings and models. New equipment like computer numerically controlled machines and three-dimensional printers and the rise of digital modeling have emphasized software proficiency over manual skills, causing older notions of creativity and craft to be reconsidered.

At the same time, the possibilities for collaboration and production opened up by computer remain threefold for architecture: a retrenchment and consolidation that reasserts centric disciplinarity, an expansion that dilutes architecture' disciplinary specificity, or transdisciplinary redefinitions and reconfigurations that both intensify and attenuate architecture's identity and limits.

Of the three transdisciplinary redefinitions offer the most promise. Computation is the foundational language of the digital and this shared language creates opportunities for engagement across design disciplines. In connection with the rise of digital culture, the contribution of architecture may very well lie in the domain of augmented reality, that is, dealing with the interface between the physical and the virtual, rather than focusing almost exclusively on the latter. It is not by accident that an institution like the MIT Media Lab, works mainly on questions of interface, is affiliated with a school of architecture. As Negroponte foresaw it - correctly - that interface would one day become an architectural problem. 


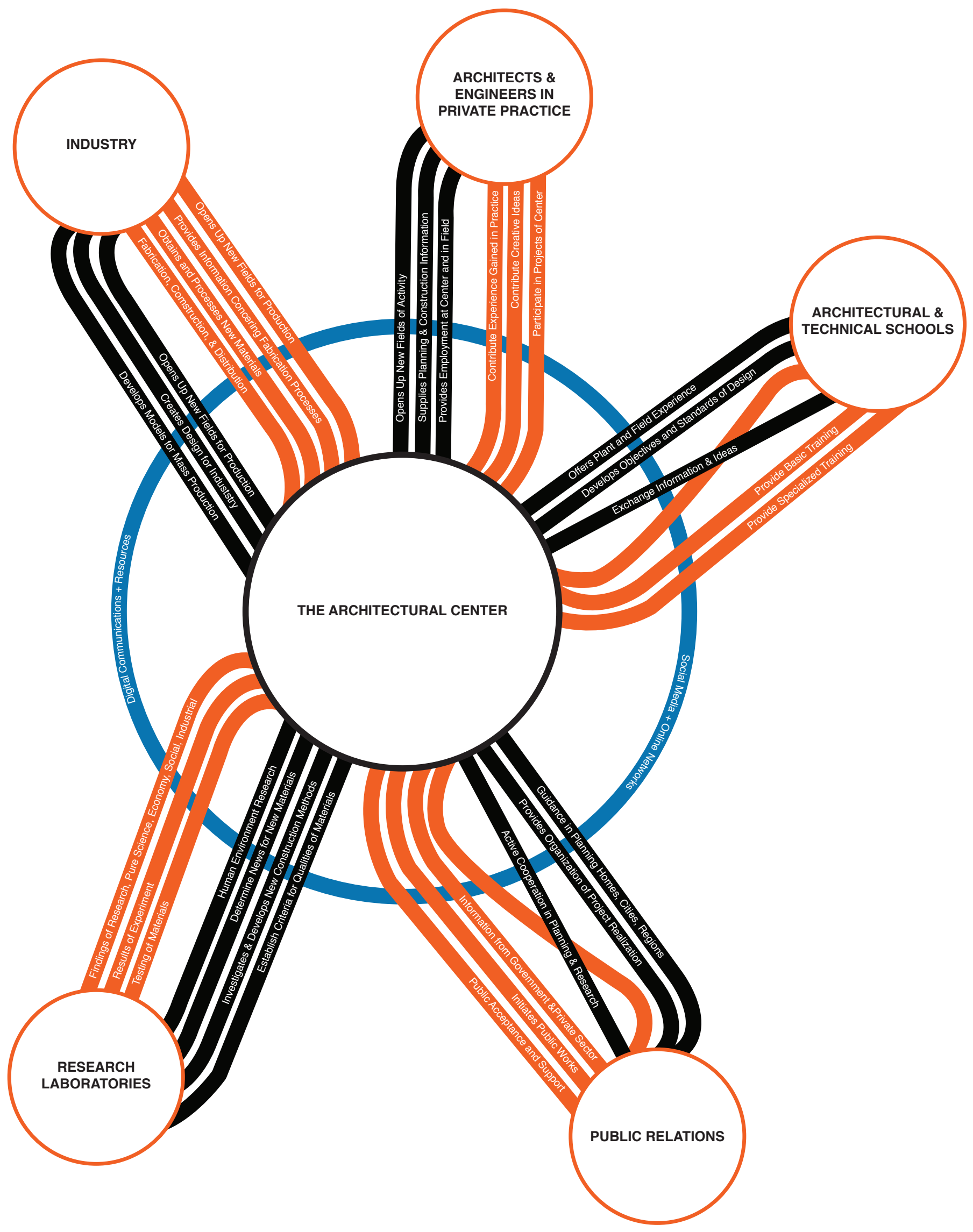

Figure 3. Redrawn from diagram by Herbert Matter originally published in "The Architectural Center: An Organization to Coordinate Building Research, Planning, Design, and Costruction," New Pencil Points, July 1943. 
As architectural education becomes increasingly invested in the teaching and methods of computation the act of construction has never before been a more important counterpoint. Contemporary architecture schools are tasked with introducing digital technologies as they are changing, creating an opportunity to develop innovative curricula and democratize access to these skills. As the Bauhaus proclaimed the goal must be to educate future designers to engage realistically with contemporary modes of production and to forge a relationship between artistic culture and industrial production.

\section{EXPANDED PEDAGOGY}

Achieving a unity of art and technology in an architectural curriculum requires an adaptation of the original Bauhaus curriculum. (Figure 2) In response to the advent of computational and digital technologies this new curricular model expands the preliminary course to include the introduction of common computational language, digital literacy, digital media, and digital fabrication. At the core of the curriculum is the integration of computation and construction as the culminating workshop of the curriculum. By combining computation with construction making is presented as a way of learning both about materials and about their digital representations. Therefore, materiality is presented as a method for combating the dysphoria of contemporary life and the visual supremacy of digital practice.

\section{COMPUTATION + CONSTRUCTION}

"Computation and materiality now seem inseparable at every level, from the macro- to the micro and nanoscales." -Antoine Picon

Bauhaus modernism paid remote attention to generic and somewhat abstract formulations of social issues. Its translation to the North American context brought with it a particularly American blend of idealism with pragmatism. Gropius placed workshops at the center of a progressive curriculum that aimed to fuse craft and design education with avant-garde artistic practice. In doing so, the Bauhaus methods of architectural learning-by-doing often linked experiential education with both the social agenda of modern architecture and technological experimentation. This pedagogy cultivated a culture of making through workshop based teaching - one of the goals of which was to train designers for industrial production and construction. These collaborative work-sites evolved into the digital tooled design/build studios of present day. Design/Build is a unique architectural education model of project-based learning that empowers students to construct their designs in collaboration with local communities. Digital Fabrication leverages computer-aided design/manufacturing technologies and integrates tools from the aerospace, automotive, and shipbuilding industries. It has altered both the way buildings are conceived and manufactured. The combination of these disciplines allows for direct, hands-on engagement with technology and challenges students to explore methodologies poised to have an innovative impact on the future of the architectural academy and profession.

When computation is leveraged in the construction of space the Bauhaus project is most fully realized in the unity of art and technology. By this definition the Bauhaus is currently located in a collection of academic and non-profits in pursuit of these ideals: MIT Media Lab, Rural Studio, Design Corps, Structures for Inclusion conference, Public Architecture, Studio 804, to name only a few.

\section{THE ARCHITECTURE CENTER}

"Eventually architecture's status may be that it becomes a fixture of the university-as a testament of the plenitude of an earlier humanism-next to the Classics Department, as just another repository of dead languages." - John McMorrough Design for the Apocalypse

What would the structure of this revised and relevant discipline look like? The Architecture Center, proposed by A Lawrence Kocher and Howard Dearstyne, in 1943, offers an idea. Kocher and Dearstyne were instructors at the Black Mountain College a uniquely American strain of Bauhaus' pedagogy. The Center was to act as a national clearing-house for building research, planning, design, and construction. It would provide fabrication and assembly shops and testing facilities, set up branch units, and create a media arm that would implement a program of lectures, radio broadcasts (now web media), exhibitions, and publications to education the general public about contemporary architecture. It's central objective - to forge new relationships between architects and industry proved prescient and is still relevant. Figure 3, is a redrawn from Herbert Matter's original graphic presented in New Pencil Points magazine. The original (and still valid) structure and organization remain relevant, the author has added the blue circle to indicate the addition of a unifying digital and social network presence, a technology that did exist at the time but which could allow an organization such as The Architectural Center to flourish in the contemporary discourse. An organization such as The Architectural Center, could provide the unity of technology, education, and practice that the discipline needs to maintain relevance.

\section{CONCLUSION}

Digital worlds should not be seen as alternatives or substitutes for the built world, but rather as an additional dimension which allows architects a new freedom of movement in the physical world. In other words, the transcendence of physicality in the digital world allows architects to extend their agency in the physical world. (Carpo, 10)

Digital craft brings together the physical and digital worlds thereby creating the unity of arts and technology Gropius called for in his Proclamation of the Bauhaus nearly one hundred years ago. The historic and theoretic framework presented here aims to move forward the project of the Bauhaus into the present day, and in doing so offers a theoretical position for a more progressive introduction to computation and construction in contemporary architectural pedagogy.

\section{ENDNOTES}

1. Arendt, Hannah. The Human Condition. Chicago: University of Chicago Press, 1958

2. Carpo, Mario. The Digital Turn In Architecture 1992-2012: Ad Reader Wiley, 2012

3. Deamer, Peggy and Phillip G. Bernstein. Building (In) The Future: Recasting Labor in Architecture. New York: Princeton Architectural Press, 2010.

4. Dewey, John. How We Think. Boston: Dc Heath \& Company Publishers, 1910

5. Diderot, Denis Encyclopedia, Or Classified Dictionary Of Sciences, Arts, And Trades, France, 1747-1765. 
6. McCullough, Malcolm. Abstracting Craft: The Practiced Digital Hand. Cambridge: The MIT Press, 1996.

7. McMorrough, John. Design for the Apocolypse. C-Lab. Volume 20: Storytelling, 2009.

8. Negroponte, Nicholas. Being Digital. New York. Knopf 1995

9. Pye, David. The Nature and Art of Workmanship. Cambridge: The University Press, 1968.

10. Piano, Renzo. "Renzo Piano Building Workshop: In Search of Balance," Process Architecture. Tokyo, Japan, N.100, 1992

11. Picon, Antoine. Digital Culture in Architecture: An Introduction for the Design Professions. Birkhauser GmbH, 2010.

12. Ranceiere, Jacques. The Philosopher and His Poor. Durham [N.C.]: Duke University Press, 2004.

13. Ruskin, John. "The Crown of Wild Olive, Lecture Iv". The Future of England, Section 151, 1866.

14. Scarry, Elaine. The Body In Pain: The Making And Unmaking Of The World. New York: Oxford University Press, 1985.

15. Sennet, Richard. The Craftsman. New Haven: Yale University Press, 2008.

16. Smith, Adam. The Theory Of Moral Sentiments New York, N.Y.: Penguin Books 2009 